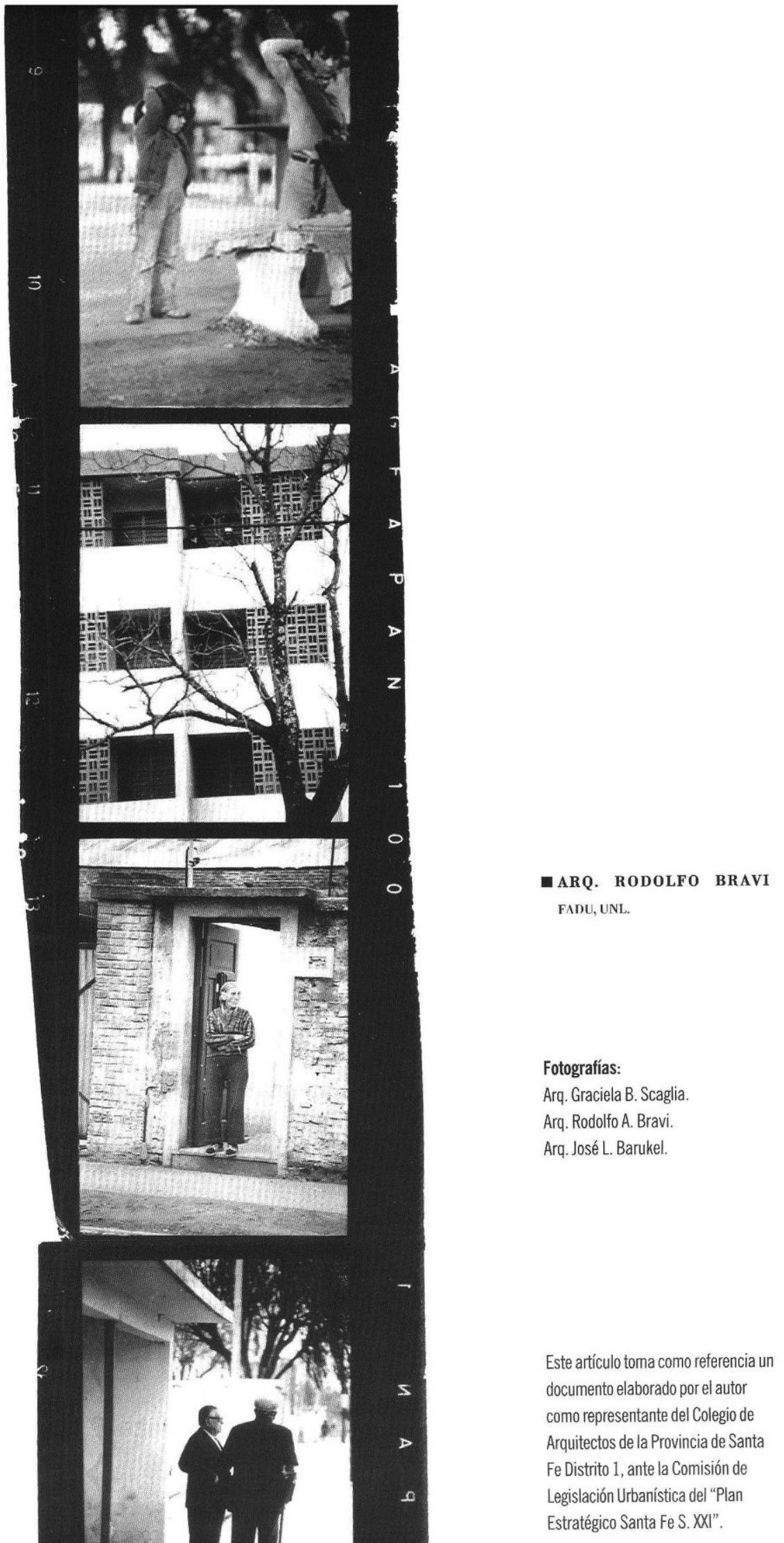




\section{Plan estratégico}

\section{PARA LA CIUDAD}

\section{de Santa Fe}

Introducción

Nuevas condiciones en el entorno sociopolítico demandan la adecuación de la legislación urbanística a este nuevo contexto. Pero la acción debe orientarse en sentido de la superación de planes urbanísticos tradicionales, cuyo único objetivo es el control de la conformación física de la ciudad, para asumir la construcción de una auténtica "actitud estratégica" como motivo de consenso entre sus ciudadanos.

El objetivo principal será la determinación del perfil de la ciudad que los santafesinos queremos, el mejoramiento de la calidad de vida a través del desarrollo sostenido, en el marco de una democracia participativa y eficaz, en el sentido de lograr una ciudad mejor para las generaciones futuras. Tal cual lo expresa Alfredo Rodríguez en su texto Por una ciudad democrática, ciudad-ciudadano poseen una raíz filológica común con habitar y participar, a partir de la conceptualización elaborada por Marsiglio de Padua en el S. XIV contraponiendo a la del origen divino de la autoridad, la tesis ascendente, es decir, el poder localizado en el conjunto de los ciudadanos quienes lo delegan en sus gobernantes. La crisis contemporánea de las ciudades latinoamericanas está referida a la problemática del hábitat como reto por lograr alojamiento adecuado para las mayorías populares que carecen de él, redistribución de la riqueza social y generación de empleo productivo, mejora y extensión de los servicios públicos, provisión de la infraestructura básica que configure un nuevo espacio urbano, construcción de una verdadera cultura urbana democrática con gobiernos locales que propicien la participación ciudadana, aspectos a los que debe agregarse necesariamente la cuestión del ocio y el disfrute de la vida en nuestras ciudades.

Sobre fines del siglo XX es creciente la preocupación acerca de los problemas ambientales y los consecuentes esfuerzos para mejorar la calidad de vida. Este concepto está, en el caso de los centros urbanos, ligado a una gran cantidad de factores debiendo destacarse la adecuada proporción de espacios verdes, la accesibilidad a las zonas de trabajo, servicio y esparcimiento, la eficiente circulación vehicular con la menor interferencia con la peatonal, la "limpieza" de agua, aire y tierra - a través del alejamiento de las fuentes de contaminación y el tratamiento de los efluentes contaminantes-, el acceso a servicios hoy considerados indispensables como agua potable, gas y electricidad. La seguridad y el trabajo son aspectos que, en el nuevo panorama de progresivo abandono por parte del Estado nacional y provincial de sus obligaciones principales, creemos deben ser abordados por la gestión municipal. ${ }^{(1)}$

El irreversible proceso de transformaciones, que incluye entre otros efectos la privatización de las relaciones sociales, debe servir como punto de partida para poner en práctica proce- 

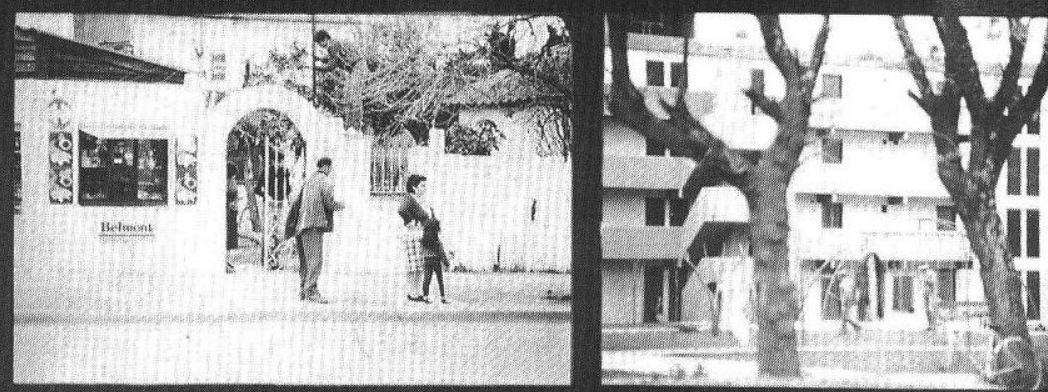

$\rightarrow 34$

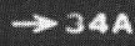

$\rightarrow 35$

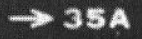

sos de descentralización y gestión participativa encaminados a consensuar un proyecto político conjunto en construcción permanente.

Tanto Pedro Santana R. en Bogotá hoy: la crisis política y administrativa de la ciudad, como Jordi Borja en Por unos municipios democráticos, presentan la necesidad de replantear los instrumentos de planificación urbana tradicionales. Sin despreciar el saber profesional, debe enfrentarse a un nuevo reto: la participación ciudadana en la generación de planes, proyectos y programas y, mas aún, en su ejecución. ${ }^{(2)}$

\section{Noción de plan estratégico y sus implicancias}

La noción de Plan Estratégico que tiene su origen en las grandes empresas fue aplicada por primera vez a las ciudades en los inicios de los años ochenta. Las mismas son consideradas como organismos en un entorno competitivo, que demanda ventajas diferenciadas a efectos de atraer inversiones.

La ciudad de Santa Fe posee una posición geopolítica sobresaliente en el nuevo entorno del Mercosur, que debe ser explotada en toda su dimensión enfocando los esfuerzos principales a sacarla del estancamiento en que se encuentra como consecuencia de incorrectas decisiones políticas y falta de orientación de la iniciativa privada, proyectándola al nuevo contexto internacional.

Precisamente, la construcción del consenso entre los medios privados y públicos representa una característica específica de estos planes que más alientan su aplicación. ${ }^{(3)}$

Por entender que constituye un buen ejemplo, nos interesa describir algunos aspectos organizativos del Plan Estratégico de Valencia que ha sido configurado en tres etapas: de elaboración, de implantación y control y de reprogramación. La primera de ellas cuenta con cuatro fases: diseño y organización, diagnóstico, construcción de los escenarios de futuro y determinación del objetivo central y líneas estratégicas y elaboración de objetivos, proyectos y acciones.

La fase I tiene por finalidad la creación de la estructura direccional del plan, que se articula en torno de los órganos permanentes de participación: el Comité Ejecutivo — que es el órgano director que asume la responsabilidad y compromiso de elaborar el Plan-y el Consejo General. El primero está integrado por el Ayuntamiento (Municipio), la Generalitat Valenciana (región), Diputación de Valencia, Asociación de Agricultores, Autoridad Portuaria, Cámara Oficial de Comercio, Comisiones Obreras, Confederación Empresarial de la Pequeña y Mediana Empresa Valenciana, Confederación Empresarial Valenciana, Consell Metropolitá de I horta, Feria Muestrario Internacional de Valencia, Unión Autonómica CSI-CSIF, Unión General de Trabajadores, Unión Gremial, Universitat de Valencia y Universidad Politécnica de Valencia.

A su vez, el Consejo General es el órgano de máxima participación institucional y ciudadana, siendo su función profundizar en los análisis técnicos y validar las conclusiones obtenidas en cada fase. Está constituido por cerca de 200 entidades, entre las que se incluyen: todos los bloques de los partidos políticos con representación municipal, oficinas técnicas municipales, colegios oficiales de profesionales, compañías proveedoras de servicios y transportes, medios de difusión, consejos regionales de desarrollo, municipios vecinos, organizaciones no gubernamentales, asociaciones y gremios empresarios, entidades bancarias locales, clubes deportivos, organizaciones de consumidores y otros. La fase II de diagnóstico tiene por propósito obtener el análisis DAFO (documentos base para el diagnóstico de la ciudad y su entorno), incluyendo Debilidades, Amenazas, Fortalezas y Oportunidades de la situación socioeconómica de Valencia en su entorno metropolitano. Se lleva a cabo a través de:

Un estudio cualitativo basado en la metodología Delphi, realizado mediante entrevistas en profundidad para conocer la opinión de los principales agentes económicos y sociales valencianos, a fin de identificar los "temas críticos" que configuran la realidad actual y pueden condicionar la evolución futura de la ciudad.

Un estudio cuantitativo: una vez detectados los temas críticos, se lleva a cabo un exhaustivo análisis de los mismos a nivel comparativo con otras ciudades del Arco 


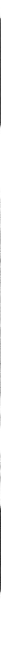

Mediterráneo Europeo de similares características, que concluye con el análisis DAFO.

Por último, una profundización del análisis DAFO de cada tema crítico a fin de identificar la posición competitiva de Valencia, a través del debate de expertos profesionales reunidos en los denominados Grupos de Diagnóstico (uno por cada tema crítico), en los que trabajaron 257 expertos de más de 55 entidades. Los Grupos de Diagnóstico fueron los siguientes:

- Infraestructura de accesibilidad y movilidad interna, presidido por el decano del Colegio.

- Oficial de Ingenieros de Caminos, Canales y Puertos de Valencia.

- Aspectos medioambientales y la huerta de Valencia, presidido por un catedrático de Economía, Sociología y Política Agraria de la ETS de Ingenieros Agrónomos, Universidad Politécnica de Valencia.

- Evolución de la ciudad y su espacio urbano, presidido por el decano-presidente del Colegio Oficial de Arquitectos de la Ciudad Valenciana.

- Dinámica sociodemográfica y cohesión social, presidido por el titular de Sociología de la Universitat de Valencia.

- Formación de recursos humanos, presidido por el director del Centro de Formación Empresarial "Lluis Vives".

- Factores de atracción culturales, presidido por el director del Conservatorio Superior de Música.

- Industria y servicios a las empresas, encabezado por el presidente de Comercial Internacional Hoyos.

Por otra parte, la ciudad de Santa Fe cuenta como importante ventaja estratégica la posibilidad de utilizar en su beneficio la extraordinaria capacidad instalada en lo referente a educación e investigación: sus tres Universidades y numerosos institutos de investigación la posicionan en inmejorable situación considerando que constituye un consenso entre las ideas contemporáneas en cuanto a que el mejor capital con que pueda contar una sociedad de cara al próximo siglo habrá de ser el conocimiento.
Por ejemplo, el Plan Estratégico del Baix Llobregat propone potenciar la base industrial, mejorando la competitividad de las empresas, asegurando la continuidad generacional de la empresa familiar, incrementando la utilización de las nuevas tecnologías de telecomunicaciones e impulsando las relaciones entre universidad y empresas, aprovechando en este sentido la instalación del campus de la Universitat Politécnica de Catalunya en Castelldefels. ${ }^{(4)}$

Sobre la ciudad se han aplicado, anteriormente, procesos de planificación los que han intentado orientar el crecimiento y mejorar la calidad de vida, por lo que partimos en este sentido de una buena posición; pero la planificación tradicional ha demostrado limitaciones por su rigidez, estatismo, limitada participación y énfasis en el producto respecto del proceso. La planificación urbana ha sido iniciativa del poder central y se ha concentrado hasta ahora en el ordenamiento de toda la ciudad, tendiendo a la generalización en los niveles de análisis, sin destacar los problemas de zonas específicas. Se pierde así la posibilidad de contemplar las particularidades de las áreas locales, proponiendo cambios ya que en esa escala no resulta difícil satisfacer las necesidades de los habitantes.

La actuación del Municipio se reduce al control de aquellas partes de la ciudad incluidas dentro del mercado inmobiliario formal, basadas en las ordenanzas de zonificación.

El desarrollo del conglomerado, que ya alcanza casi el medio millón de habitantes, requiere de la comprensión de las muy diversas tensiones que intervienen en el fenómeno urbano y de la firme convicción de sus autoridades respecto de la necesidad de planificar su crecimiento, con el consenso y la participación de los actores sociales. Aspectos tales como la especialización de áreas - como por ejemplo la central de Santa Fe-, la sistematización de los espacios verdes, vías de comunicación, áreas destinadas a nuevas urbanizaciones, densidades, carácter, zonas de recreación y esparcimiento y tendido de servicios esenciales en la vida urbana contemporánea, deben tener un ámbito de discusión apropiado y un organismo de toma de decisiones. 


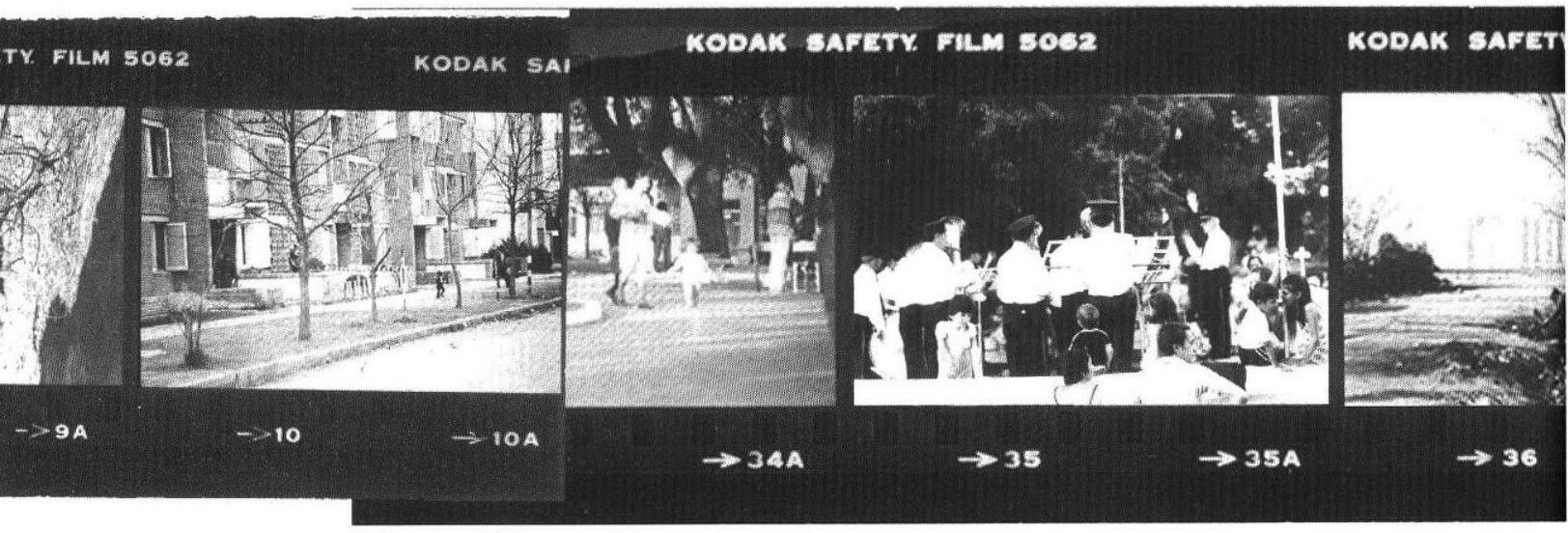

Por otra parte, salvo en un corto período, la estructura del mismo Departamento Ejecutivo Municipal demuestra la escasa atención que merece la planificación de la ciudad, por cuanto Planeamiento Urbano ora es una Dirección ora una Subsecretaría con escaso presupuesto.

No deseamos un Plan "de laboratorio" que se proyecte sin consultar a organismos e instituciones interesadas y especialistas en el tema (colegios profesionales, universidades, vecinales, otros organismos y al propio ciudadano común, destinatario al fin de las consecuencias).

Nuestro principal anhelo consiste en lograr una plena consustanciación de la ciudadanía con los objetivos del plan, intensificar su relación y acortar la distancia con sus gobernantes. Para ello, proponemos adoptar el concepto de una planificación flexible que apunte hacia una gestión más efectiva, estudiando la ciudad por partes, en función de determinadas estrategias del conjunto urbano, siendo las obras resultado de la aplicación de criterios de prioridad. La agudización de la crisis económica tiene en el cordón del Gran Santa Fe una de sus expresiones físicas mas acabadas. Las estadísticas oficiales señalan que la concentración de la riqueza ha provocado que entre 1990 y 1997 el décimo de la población más rica duplicara la proporción de ingresos respecto de la misma porción más pobre. Por otra parte, entre Santa Fe-Santo Tomé, 60.000 personas sobreviven con un ingreso promedio mensual de 45 dólares. Ningún análisis serio puede realizarse ignorando esta realidad y ningún plan tendrá éxito desde nuestro punto de vista si no considera prioritario revertir esta situación.

Apostar a las pequeñas y medianas empresas es la opción razonable a fin de brindar nuevas alternativas de inversión y desarrollo, propuestas que pueden y deben ser promovidas por el Municipio.

\section{Geopolítica}

\section{Las transformaciones territoriales y las obras públicas}

Las nuevas tendencias en la comercialización de productos y servicios posicionan a la ciudad en situación inmejorable respecto de los corredores mas importantes en sentido nortesur y este-oeste.

Sin embargo, la falta de realización de obras públicas de extrema necesidad y gran envergadura puede relegarla a la difícil situación de "estar dentro pero fuera", o de ver pasar la oportunidad de devolverla a la de la floreciente Santa Fe de principios de siglo.

La proximidad del fin de la vida útil del Túnel Subfluvial "Uranga-Sylvestre Begnis", la estrechez de la vía de tránsito vehicular que nos comunica con Córdoba y todo el oeste argentino y Chile, la interrupción del ramal ferroviario en el mismo tramo y la obsolescencia del Puente Carretero Santa Fe-Santo Tomé, así como la falta de concreción del proyecto de hidrovía y las vicisitudes que atraviesa regularmente la Estación área de Sauce Viejo, descubren a nuestro juicio las mayores debilidades de la ciudad al respecto.

Debe agregarse una serie de obras claramente indispensables a los intereses de situar a la ciudad en este entorno económico y que entendemos deben promoverse desde el Municipio local, alentando la participación del capital privado. Ellas se relacionan con las vías de comunicación interna de bienes y servicios, tales como reactivación de vías ferroviarias, interconexión de rutas de autotransporte $(11,19$ y 168$)$ y su recorrido dentro de la trama urbana de la ciudad, estaciones de carga y transferencia intermodales, puntos de comercialización de la producción regional y desarrollo de las nuevas tecnologías de telecomunicaciones.

Creemos con firmeza que fundamentalmente en estos aspectos se juega Santa Fe su futuro competitivo.

\section{Metrópolis y Estructura}

\section{Tamaño, densidad y roles. Legislación para la ciudad}

La aplicación de legislación urbanística en las ciudades de nuestra región ha tenido un efecto disímil, aunque puede afirmarse que en términos generales ha contribuido a ordenar de alguna manera su crecimiento y densificación, coadyuvando a evitar el agravamiento de los desequilibrios propios del subdesarrollo. 


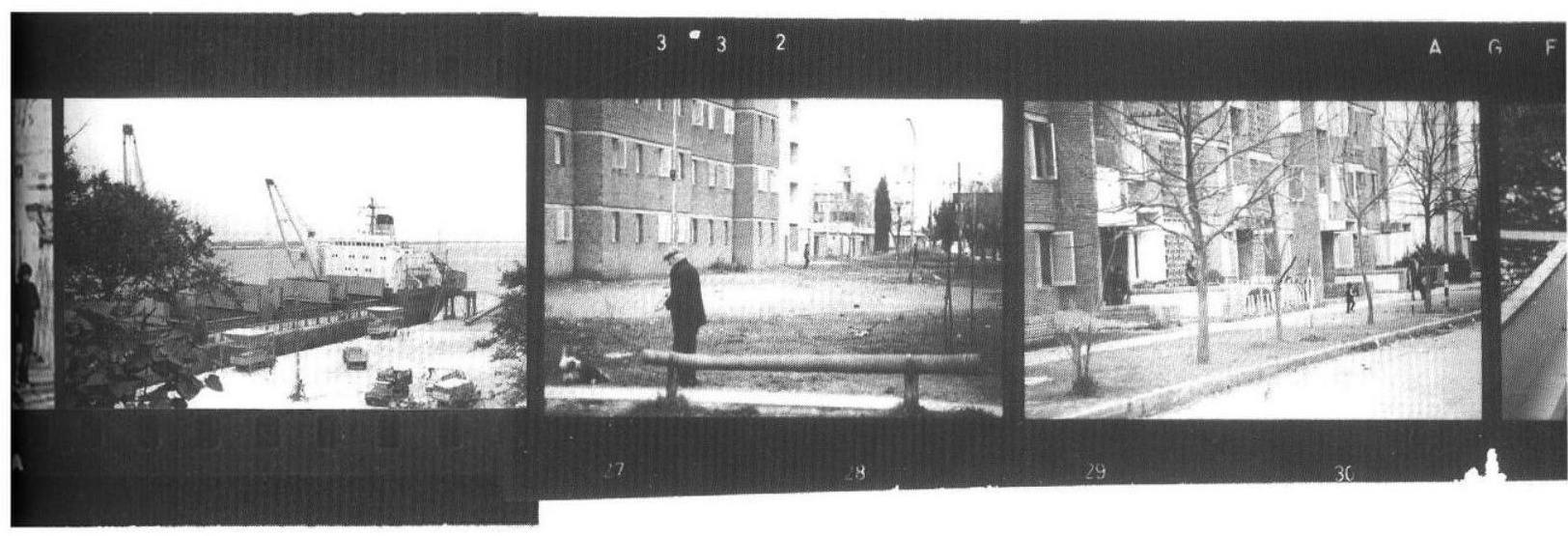

Sin embargo, son notables las diferencias entre las distintas oleadas inmigratorias y sus consecuencias en cuanto al fenómeno de inclusión-exclusión.

En tanto, el primer gran crecimiento de Santa Fe se dio como ampliación de la "ciudad legal", incluyendo a los inmigrantes entre los beneficiarios de la vida urbana en coincidencia con la modernización institucional que vivió nuestro país; en el segundo proceso (esta vez interno), que coincidió con cierta mecanización del campo por lo que los obreros rurales buscaban trabajo y mejores condiciones de vida en la ciudad, cierta industrialización que vivió la región permitió su incorporación al trabajo ya sea en éstas o en empresas estatales de transporte o servicios.

La tercera ola resulta ser la más perjudicada. Procede de ciudades pauperizadas del norte y noroeste cuya actividad tiende a hacerse nula, en el marco de una creciente centralización de la producción. Su preparación es insuficiente para enfrentar los trabajos originados en la "tercerizada" ciudad contemporánea. Mientras sus expectativas se reducen drásticamente, aumentan los procesos de segregación y marginalidad. ${ }^{(5)}$

El abandono por parte del Estado del control de los servicios públicos (parte importante de la conformación de la calidad de vida urbana actual) hace que se cargue de responsabilidad al Municipio por sus falencias, no encontrándose sus estructuras en condiciones de responder a este requerimiento. Por otra parte, y en referencia directa a la legislación actual, puede advertirse su dificultosa interpretación, ciertas contradicciones entre los distintos reglamentos, así como la falta de difusión de las ordenanzas entre los ciudadanos.

La otra cuestión de la misma importancia se relaciona con la creciente complejidad del fenómeno urbano y la consecuente necesidad de interpretar de manera diferenciada sus distintas áreas, promoviendo al mismo tiempo enfatizar su carácter. La determinación de áreas en las que la iniciativa privada pueda desarrollar proyectos de inversión contribuirá también a aumentar la actividad, con la consecuente mejora en el nivel de empleo e ingresos.

\section{Crecimiento y suburbios}

El crecimiento de nuestras ciudades de economías no consolidadas se realiza sobre la base de la iniciativa privada, con la pretensión por parte del Estado de ejercer el control. La falta de coincidencia de las manchas de crecimiento con las de infraestructura y el crecimiento discontinuado generan altos costos de tendido de redes. Se origina así un sistema perverso en el que los barrios se asientan sobre áreas sin servicio de infraestructura debido al bajo costo de los terrenos para posteriormente exigir al Estado su provisión. Creemos firmemente en la necesidad de consensuar criterios y en consolidar crecimientos intersticiales a efectos de bajar dichos costos. Estudiar la ciudad por partes lleva implícita la posibilidad de establecer diferentes densidades ajustándolas con la oferta de infraestructura y la aptitud portante del terreno, generando un nuevo tipo de consenso entre el habitante, el inversor privado, la empresa constructora, las empresas proveedoras de servicio y el propio Estado. Una pregunta que corresponde hacernos es si debe limitarse el crecimiento de la ciudad. De hecho, el Municipio ha autorizado loteos en áreas no previstas, con tamaños de lotes y disposiciones urbanísticas correspondientes a otros distritos. Viviendas suburbanas (en cuanto a su densidad), con lotes de $10 \times 20$ metros y espacios verdes pequeños. Hasta ahora, no ha existido una planificación previa integral del crecimiento en la provisión de infraestructura, sino solamente un proceso incremental diseñado para aminorar los problemas surgidos como consecuencia de la urbanización. La privatización de las empresas públicas, que parece por una parte haber paliado la falta de inversión en extensión de redes, y ha dejado a merced de las leyes del mercado a los sectores mas desprotegidos de la sociedad, ante la falta de control por parte del Estado. No parecen resueltos, por otra parte, los umbrales que requieren grandes inversiones y planificación conjunta.

La liberación de terrenos urbanos ocupados anteriormente por instalaciones ferroviarias es un problema relativamente nuevo que enfrentan los urbanistas. El importante desarrollo 
de los Ferrocarriles en nuestro país a principios de siglo obedeció a la necesidad de dar salida a la producción primaria de nuestra región pampeana. Contamos con la oportunidad de resolver las dificultades planteadas por una traza de ferrocarriles que no tuvo en cuenta el crecimiento de los núcleos urbanos, cerrando extensas porciones de territorio y degradando en muchos casos su calidad ambiental. Paradógicamente, ello ha permitido contar con este territorio urbano que no ha sido afectado por el crecimiento a veces anómalo de las ciudades, quedando como reservas vírgenes frente a la especulación.

Resulta indispensable programar las intervenciones sobre estas porciones de territorio, de manera que no sólo corrijan defectos en la trama urbana de la ciudad, sino que contribuyan fuertemente a promover acciones y emprendimientos transformadores.

Respecto de la ocupación de tierras por parte de nuevos pobladores, el Estado Municipal, al considerar a las invasiones como espontáneas, no actủa para evitar la ocupación de áreas no aptas para el desarrollo (como las inundables, por ejemplo): "es decir que existe una dicotomía entre el discurso que concibe los barrios como indeseables, fuentes de delincuencia e inestabilidad social, un fenómeno que representa una distorsión temporal en el desarrollo capitalista y las políticas concretas que unen la tolerancia de la ilegalidad con la intervención directa del Estado en la provisión de servicios o el reordenamiento de barrios".

Al respecto, las conclusiones del trabajo de John Foley y Esther Marcano sobre planes, urbanización y gestión de servicios urbanos en Barquisimeto, Venezuela, son ilustrativas de una situación probable en muchas poblaciones latinoamericanas: "Cabría preguntarse por qué el Estado venezolano actúa en forma tan desarticulada en su intervención en los barrios. Parece que la respuesta reside en el papel que juega en el proceso urbano. Por una parte, evade la resolución definitiva de los problemas a fin de mantener la comunidad en una situación de dependencia.
Las necesidades se van satisfaciendo gota a gota y así se preserva el poder político dentro de los barrios. Por otra parte, beneficia a particulares por medio de la contratación de la construcción fraccionada de servicios dentro de un esquema de clientelismo político". ${ }^{(6)}$

\section{Acerca de los suburbios ${ }^{(7)}$}

Para los urbanistas y arquitectos, las barriadas de la periferia son una mancha diferente y contraria a la lógica cartesiana de sus ciudades.

Sin embargo, es indispensable profundizar en el análisis acerca de que representan muchos millones de dólares empleados en la construcción de viviendas, pequeños negocios, locales y servicios públicos, debiendo agregar la inversión política y social en la organización de la comunidad.

Nuestra propuesta consiste en una política inclusiva de las comunidades que se han conformado en la periferia, con el objeto de trabajar en forma conjunta para su incorporación a las virtudes de la vida moderna, en el marco de sus propias aspiraciones y patrones culturales.

En cuanto a una visión espacial de los suburbios, corresponde plantear la necesidad de continuar con la estrategia de las vías de penetración y salida, dar inicio a una política municipal de construcción y reemplazo de viviendas, con la incorporación de mejores condiciones sanitarias y de servicios, siempre con la participación de las comunidades locales con el fin de contemplar sus propios requerimientos sin subvertir sus propios patrones culturales. No dudamos que ello habrá de contribuir en acentuar la tendencia de nuestra ciudad hacia una metrópolis cosmopolita que tensione fuertemente su entorno regional.

\section{Densidad ${ }^{(8)}$}

David Lewis, en La ciudad: problemas de diseño y estructura, plantea ya en la década del '70 los posibles rumbos de la urbanística de fin de siglo.

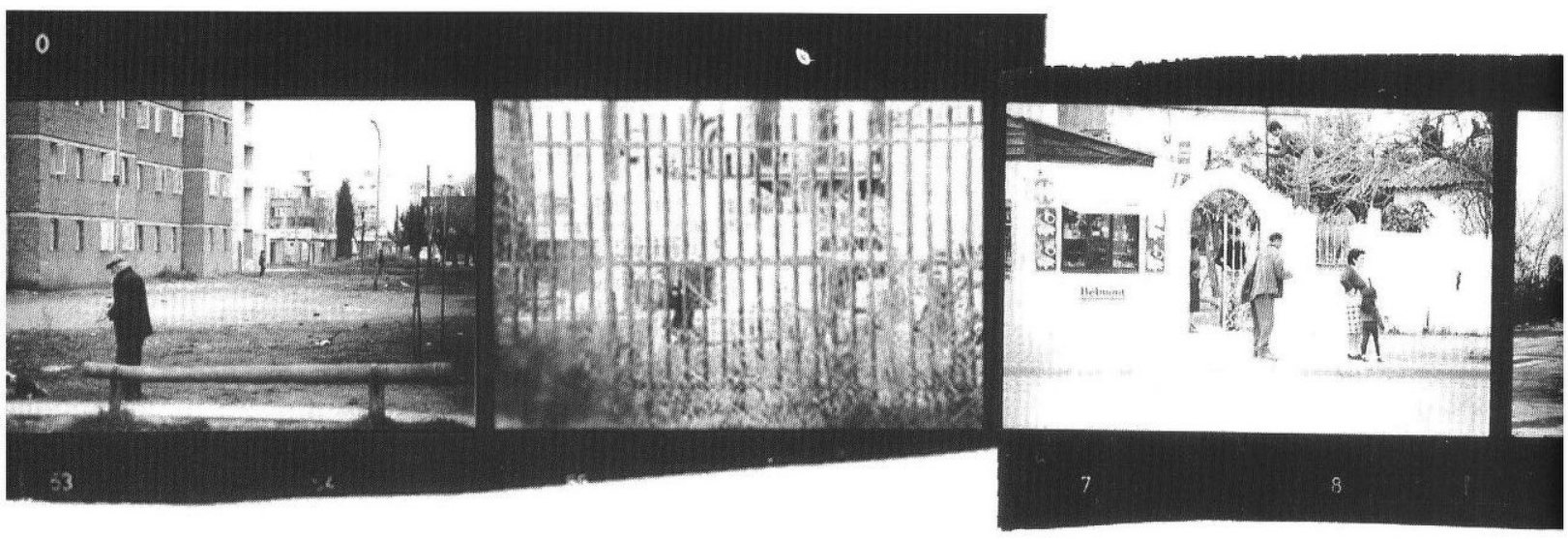


La creciente tendencia a la urbanización de los países industrializados tiene su reflejo en Asia, Africa y Amćrica Latina, continentes en los que los problemas se agravan como consecuencia de su desigual distribución de la riqueza. Estos procesos se han profundizado en la última década como consecuencia de la aplicación de políticas neoliberales, aumentando dramáticamente la distancia entre los que tienen acceso a un sustento mínimo y los que, aun habitando modernas ciudades, tienen menos posibilidades que hace un siglo atrás.

El desarrollo de la agricultura mecanizada que incluye maquinaria para sembrar, plantar y segar, fertilizantes e insecticidas fumigados desde helicópteros y aviones, las investigaciones en microclimatología aplicada al cultivo de plantas y cría de animales, la clonación de especies y las nuevas técnicas de almacenaje, conservación, congelados, deshidratación y muchas otras, no parece aún suficiente para alimentar el crecimiento desmesurado de la población de estos continentes. Alli, la necesidad de rendimientos mucho mayores depende como nunca de la ciencia, la mecanización, la administración y la distribución. Este aumento de la mecanización de la agricultura provoca migraciones a las ciudades, en las que los campesinos, sobre todo los más jóvenes, sueñan con lograr un futuro nuevo y diferente. ${ }^{(9)}$

Sin embargo, la población excluida de esos "dos mundos" posee objetivos en común: permanecer en la ciudad, alcanzar igualdad de derechos, conseguir la propiedad de parte de la ciudad para, desde dentro, ejercer presión y lograr la ciudadanía plena. La vivienda, la salud y la educación alcanzan a finales de este siglo el status de lo deseable, en una rara paradoja que parece retrotraernos 100 años. ${ }^{(10)}$

La cuestión de la densidad no puede ser analizada separadamente de otros fenómenos que construyen los distritos urbanos. Las considerables fuerzas sociales, políticas y económicas que actúan en ellos plasman sus proyectos muchas veces simultáneamente sobre el mismo espacio,

\section{Plan estratégico para la ciudad de Santa Fe}

produciendo contradicciones, sutiles costuras y continuidades. La responsabilidad de las autoridades municipales se concentra en democratizar los procesos de toma de decisiones, de manera de lograr el acceso a las virtudes de la vida contemporánea de todos los ciudadanos, propiciando la consecución de los objetivos particulares de cada sector. Las actuales tendencias a la fragmentación atentan contra la posibilidad de lograr consensos masivos, pero permiten avizorar al componente esencial de toda sociedad humana: el mismo hombre, con sus virtudes y defectos, pero con expectativas renovadas acerca de una nueva construcción social, más justa y equitativa.

Rem Koolhaas ${ }^{(11)}$ afirma que la arquitectura es una mezcla paradójica de poder e impotencia. Los proyectos urbanísticos de las décadas anteriores, basados en importantes intervenciones sobre las ciudades, debieron ceder a una más realista apreciación de la escala del lote y de los pequeños conjuntos urbanos. Otro aspecto que conspira contra esta posibilidad del urbanismo es la asincronía en la construcción de una ciudad, por lo que puede apreciarse una sucesión de proyectos superpuestos cual palimpsesto (al decir del arquitecto cordobés César Naselli), en una trama compleja y contradictoria, con interrelaciones generalmente infelices.

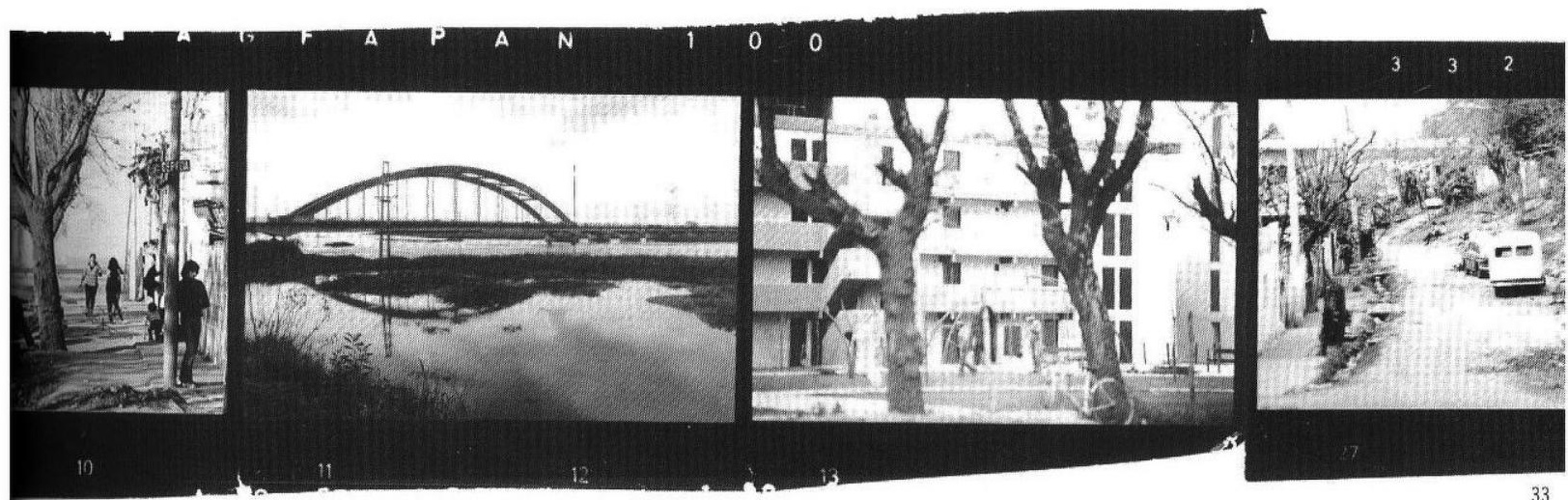


Nuestras ciudades se desarrollan a partir de tres procesos simultáneos:

* Expansión del área urbanizada, transformación de la periferia rural en ciudad.

* Consolidación, a partir de la extensión de infraestructura y equipamiento sobre la trama existente.

* Densificación, transformación de áreas consolidadas por la construcción de nuevas superficies.
La primera de las fases implica la subdivisión de la tierra, materializándose una trama en la que habrán de concretarse las relaciones entre la propiedad pública y privada, situaciones de referencia, equipamiento. En Santa Fe, en términos generales, se produce un tipo de crecimiento denominado "por analogía", en el que se da una continuidad similar a la trama existente. Ello produce una extrema monotonía, debiendo las fases sucesivas determinar casi naturalmente la adjetivación de dicha trama. La indiferenciación produce confusión y un falso equilibrio, acentuado por la gran cantidad de tiempo que demora la segunda fase de consolidación. (12)

\section{Notas}

"En este momento del siglo -todo hace prever que la situación se acelerará en el próximo- las ciudades son el espacio construido socialmente en el cual impactan con mayor contundencia las emergentes relaciones políticas, económicas, tecnológicas, comunicacionales y culturales, en definitiva: sociales, que experimentan regiones y naciones como consecuencia de lo que se denomina globalización. Del desarrollo de las potencialidades de comprender, procrear y responder que puedan efectuar las sociedades urbanas, para que se acrecienten las situaciones positivas (y se minimicen las negativas), dependerá en gran medida que las ciudades sean, en el próximo siglo, ámbitos de convivencia humana solidaria y creativa, o su contracara: acumulación de nolugares provocadores del desarraigo y la exclusión."

Storero, Hugo. "Escena Urbana", en Revista Polis, N ${ }^{\circ} 1$, Santa Fe,FADUUNL, 1998, p. 8.

2 Zárate, Marcelo. "La regulación urbana de la arquitectura". Sus implicancias en el contexto de la ciudad latinoamericana desde un enfoque ambiental de conocimiento y acción, en Revista Polis, N ${ }^{\circ} 1$, Santa Fe,FADU-UNL, 1998, p. 31

"Los concursos de ideas urbanas abiertos a profesionales, así como los centros de iniciativas locales de escala barrial, las sugerencias del Municipio en el ámbito de proyectos urbanos propulsores de inversiones y desarrollo local, pueden contribuir al diálogo intertextual a modo de hipótesis proyectuales, como un primer paso en la exploración de las posibilidades de una hermenéutica urbana. Para ello, será necesario que el Municipio asuma su rol de promotor de iniciativas, de organismo convocante de ideas e inversiones, a partir de las cuales se generen condiciones apropiadas para pensar en regular a partir del logro de mejores condiciones para el diálogo y el acuerdo. Actitud que necesariamente debe vincularse al nivel de un plan estratégico, deseable y posible para la ciudad, como objetivo de máxima. Pero un plan estratégico real, concebido y asumido por todos los sectores de la comunidad y no desde la oficina técnica del gobierno local."

3 "El Plan Estratégico se configura como un proceso ordenado $y$ cronológicamente secuencial, propio de la planificación estratégica territorial, que intensifica el principio de participación y consenso público y privado sobre el que se fundamenta, con el propósito de facilitar la posterior implicación de los agentes sociales y económicos para su puesta en práctica." Plan Estratégico de Valencia.

4 "Un Plan Estratégico es un proyecto global de ciudad que, lejos de ser un producto cerrado, rígido y acordado por unos pocos, implica inaugurar un espacio de reflexión colectiva, flexible, abierto y plural." Plan Estratégico Buenos Aires 2000. UBA, 1998.

- "La ciudad ilegal, o sea la parte de la ciudad que no admite ser controlada desde la ley, permanece en estado de alerta frente a los intereses económicos y políticos legitimados. Su compleja realidad social reclama estrategias de acción alternativas a las de la legalidad imperante, que van más allá de consideraciones estrictamente. técnicas y legales por parte del municipio." Zàrate, Marcelo. Op. cit. P. 30.

- Foley, John y Marcano, Esther: Planes, urbanización y gestión de servicios urbanos en Barquisimeto, Venezuela. S/d.

( "Los nuevos suburbios carecen de servicios públicos, son poco higiénicos y en muchos aspectos alarmantemente inseguros. Muchos observadores los consideran como una virulenta enfermedad social. Los políticos y la policía los ven como un peligroso desafío a la ley y al orden. Los conservadores están convencidos de que son focos de revolución." Mangin, William. "Squatter Settlements", Scientific American, Vol. 217. Citado en D. Lewis, La ciudad: problemas de diseño y estructura, G. Gili.

8 "El enorme (y aparentemente inevitable) crecimiento en tamaño de las ciudades no es ni malo ni alarmante en si. Depende de su estructura. De lo que tenemos que darnos cuenta es de que la ciudad del futuro no puede limitarse a ser la ciudad del presente con mayores dimensiones, del mismo modo que la ciudad actual no sigue los modelos del pasado."

Lewis, Deavid: La ciudad: problemas de diseño y estructura, G. Gili, p. 2.

9 "Los millones de la población rural de Africa, Asia y América Latina que 


\section{Plan estratégico}

\section{PARA LA CIUDAD DE}

\section{SaNTA Fe}

viven hoy sin un techo adecuado llevan consigo innumerables problemas cuando emigran a las grandes metrópolis. El desafío es no sólo en cuanto a la adaptación fisica. Es el desafío social, mucho más agudo y profundo, de las esperanzas nacientes. Los sueños dorados de las nuevas oportunidades nacidos a causa de las comunicaciones modernas. Los inmigrantes llegarán cada vez en mayor número sin trabajo, alfabetización conocimientos de las técnicas urbanas y desarraigados de las tradiciones de su tierra y de su pueblo." D. Lewis. Op. cit, p. 3.

10. "La ciudad es el más acabado reflejo de una cultura. Expresa en su estructura y expresión - en su forma- la organización de un sistema social, político, económico y cultural. El orden riguroso restringe la libertad. El modelo de ciudad unitario, ideal, perfecto, tan caro a los arquitectos y planificadores requiere para ser llevado a cabo una concentración de autoridad muy cercana a algún tipo de fascismo. La libertad implica un quantum de desorganización, de caos. La ciudad contemporánea democrática expresa en su desorden formal - en su apariencia de collage - una compleja trama de decisiones

desconcentradas, independientes y a veces contradictorias. Una democracia que funciona bien es un delicado equilibrio entre orden y libertad. Lo mismo debiera suceder con una ciudad bien estructurada. Debe haber un delicado equilibrio entre plan y flexibilidad.

El plan, quizás sería mejor llamarlo estrategia, debe contener objetivos, trazas esenciales, potenciar la funcionalidad y legibilidad en la estructura y forma de la ciudad. Pero simultáneamente, debe ser capaz de alojar la diversidad, contradicción y desorden que son el resultado de las complejas gestiones e intereses que promueven su desarrollo y son expresión de sus libertades."

Lestard, Jorge. "Apuntes sobre la ciudad, desde la arquitectura", en revista Arquis $n^{\circ} 3$, Bs. As., Universidad de Palermo, p. 40. El texto nos parece particularmente preciso acerca de nuestra visión de la ciudad y de su construcción colectiva.

11 Koolhaas, Rem and Mau, Bruce. S, M, L, XL Small, Medium, Large, Extra Large. Benedikt Taschen Verlag $\mathrm{GmbH}, 1996$. P. XiX.

12 "La paulatina adjetivación de la trama privilegia la posición relativa de ciertas zonas. Ventajas diferenciales que despiertan el interés de la gente por acceder a ellas.

Mejor acceso, mejor paisaje, mejor desarrollo comercial, incrementan el valor de un sector que debe compensar sus costos con mayor densidad." Garay, Alfredo. "Repensando las torres. Una aproximación desde el urbanismo", en revista Arquis no 3 , Bs. As., Universidad de Palermo, p. 81. El autor señala que esta dinámica ha convertido las conductas en procesos sociales, presentando las distintas fases, formas diferenciadas de vivir en la ciudad. 